\title{
Miranda
}

Revue pluridisciplinaire du monde anglophone /

Multidisciplinary peer-reviewed journal on the English-

speaking world

23 | 2021

Modernist Exceptions

\section{Pandemic Shakespeare: Perspectives on Early Modern Theatre Practice and Pedagogy in Lockdown}

Essay

Benjamin Blyth

\section{(2) OpenEdition \\ Journals}

Electronic version

URL: https://journals.openedition.org/miranda/42769

DOI: 10.4000/miranda.42769

ISSN: 2108-6559

Publisher

Université Toulouse - Jean Jaurès

\section{Electronic reference}

Benjamin Blyth, "Pandemic Shakespeare: Perspectives on Early Modern Theatre Practice and Pedagogy in Lockdown", Miranda [Online], 23 | 2021, Online since 13 October 2021, connection on 30 November 2021. URL: http://journals.openedition.org/miranda/42769 ; DOI: https://doi.org/10.4000/ miranda.42769

This text was automatically generated on 30 November 2021.

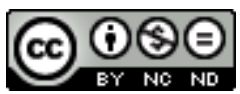

Miranda is licensed under a Creative Commons Attribution-NonCommercial-NoDerivatives 4.0 International License. 


\section{Pandemic Shakespeare: Perspectives on Early Modern Theatre Practice and Pedagogy in Lockdown}

Essay

\section{Benjamin Blyth}

1 When the pandemic hit Europe in February 2020 few could have anticipated an entire year of theatre closures. I had just finished working on a repertory season of Julius Caesar and A Midsummer Night's Dream in Edmonton, Alberta, and was preparing to travel to London to begin work on a site-responsive Romeo and Juliet in Shoreditch Church. By mid-March, however, the scale and pace of the virus forced the UK into its first "lockdown". The pandemic has shaped so much of our vocabulary during the last year that it is difficult to think back to the first appearance of this (now-ubiquitous) term, without encumbering it with the vast amount of experiential baggage it has collected over the last twelve months. With no prior experience of "lockdown", no concept of its extent or implications, and no timeline for the reopening of the theatres; it became clear that the conditions of the pandemic called for an urgent reappraisal of my artistic and pedagogical principles. The question then became how to best adapt my practice and pedagogy to this new life in "lockdown"?

2 With this paper, I will reflect on some of the outcomes from a year of digital experimentations with Shakespeare's texts on Zoom. I consider two main branches of online practice this year, and these are handled broadly chronologically. The first is "Shakespeare Sunday," a play-reading and discussion series with an international cohort of participants. The second is the "Isolation Across Borders" series of online performances of highly emended Shakespeare plays by Malachite Theatre, ${ }^{1}$ which were live streamed from lockdown in the spring. The project featured an international company of actors from the UK and Canada and was supported by the National Arts Centre of Canada's \#CanadaPerforms series, which live-streamed the show at $2 \mathrm{pm}$ Eastern (12.00 Mountain, 19.00 BST) on the NAC Facebook page. Although Zoom performance has become something of an unloved child of this remarkable historical 
moment, I argue that these explorations have resulted in a surprising range of benefits that I hope to retain in my post-pandemic practice.

"Shakespeare Sunday" began on 22 March (the day before the UK entered national lockdown) and ran for sixteen weeks during the first wave of the virus. The idea behind the event was to host a weekly play-reading and discussion group that maintained a sense of community for participants affected by lockdown. The series was open to all members of the public and each reading was advertised in advance on Malachite Theatre's social media accounts. The company has produced work across the UK and Canada and has developed a large following in both North America and Europe. With that in mind, I arranged to host the readings at a time that would best encourage transAtlantic participation (11.00 Mountain, 13.00 Eastern, 18.00 GMT). Fortunately, the gambit was successful, and the series drew participants from the USA, Canada, Mexico, France, Netherlands, and the UK in its opening weeks. Those attending included a number of actors who wanted to continue practicing their craft during the theatre closures, audience members from previous Malachite shows, individuals with no connection to the company but an interest in early modern drama, and family and friends of other participants. The group represented a wide range of backgrounds and occupations, with each reader bringing a distinctive perspective to their role and the subsequent discussion.

With this community-building purpose in mind, I made a conscious effort to reduce barriers of entry wherever possible. Participants were required to download the Zoom app before attending their first session, as these early meetings were held exclusively on the platform. ${ }^{2}$ There was no requirement to stay for the whole event and the room was open to all those who expressed an interest, so members would frequently come and go during the sessions. While we had some legitimate concerns about Internet safety and online etiquette, we were fortunate not suffer any incidences of "Zoombombing" during the series and sent passwords to all those who registered in advance when the new protocol came in during April.

Figure 1

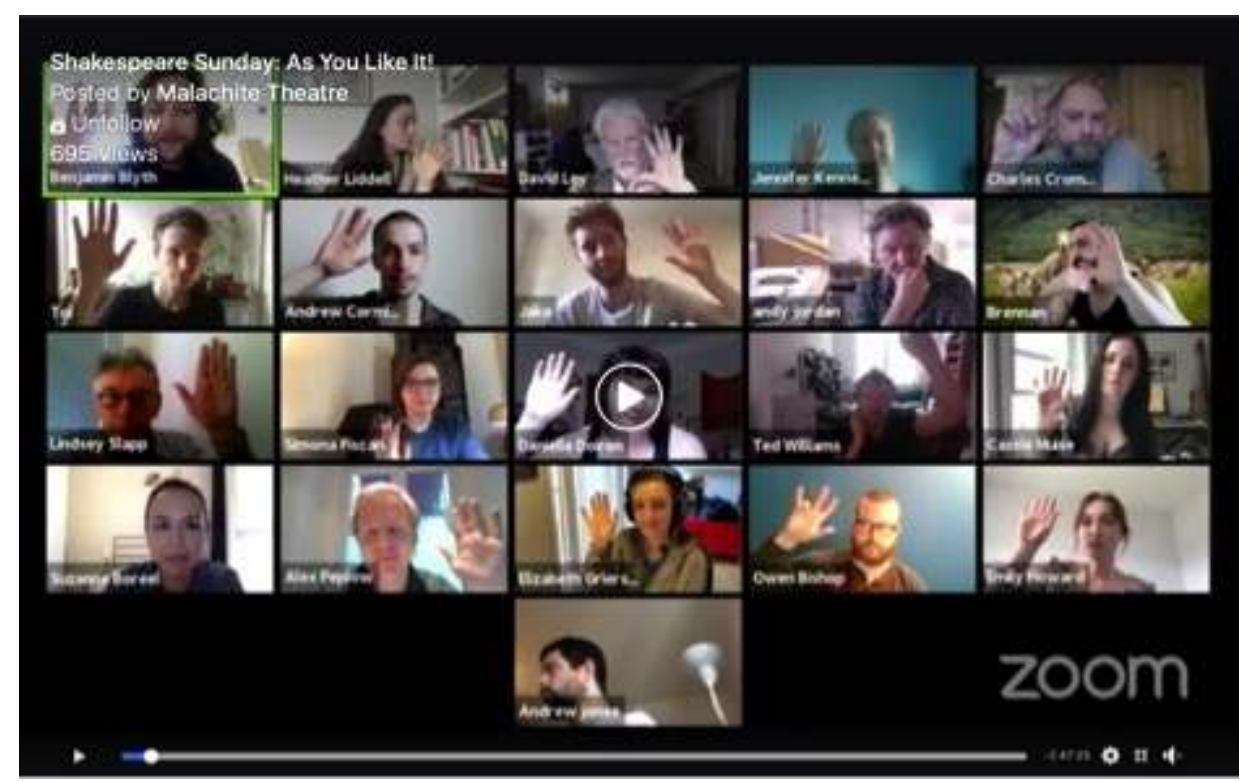

Malachite Theatre, "Shakespeare Sunday: As You Like It!" Facebook, May 17, 2020, www.facebook.com/466013643488097/videos/708121076623389 
5 I was keen to keep the event as informal as possible but did impose a degree of structure on its management and delivery. The company would advertise the forthcoming "Shakespeare Sunday" on social media a week in advance and note the names of interested participants. People would send in requests to join, read, or in specific cases request certain favourite roles. The casting process, such as it was, was handled on a first-come-first-served basis. I provided a brief synopsis of the play's major themes before each week's reading and selected three or four talking points to act as prompts for the post-show discussion (Shakespeare Sunday: The Merchant of Venice 0:45-4:32). Textual irregularities did occasionally occur but were quite rare and relatively easy to circumvent. ${ }^{3}$ Furthermore, if a participant had left their microphone on during a scene by mistake, the platform made this easy to remedy as the event's host. Sessions lasted a total of three-to-four hours with a brief intermission roughly halfway through each week's text.

6 While not strictly pedagogical in its conception, the Zoom platform responded remarkably well to the "Shakespeare Sunday" format and its potential as a teaching tool became increasingly clear in the following weeks. The chat function, for example, allowed participants to comment on dramatic moments in real time. This was particularly useful for occasions when group members identified familiar or contemporary themes in the plays. For example, the first event was a reading and discussion of Richard II. I had consciously marketed the text as a "tale of greed, isolation, privilege, and loss" ("Shakespeare Sunday: Richard II", Facebook), with the hope of encouraging the group's engagement with the play's many contemporary resonances. What I had not anticipated, however, was quite how diverse those responses would prove to be. The British participants, for example, were drawn into comparisons of John of Gaunt's "scept'red isle" (RII, 2.1.40) speech with the on-going Brexit saga. The Canadian participants, by contrast, read the same speech in relation to Trump's increasing isolationism in the United States. As the event continued through April and May, so too the post-show discussions responded to developments in global news cycles. The group read The Merchant of Venice, for example, in the week following the murder of George Floyd. The post-show discussion was dominated by questions of how to approach intersectional violence in the twenty-first century. Shakespeare's play provided an effective conduit into these discussions, which I attempted to keep closely rooted in textual examples. That the event reached across generational (as well as the geographical) divides proved to be particularly fascinating in this discussion. In this way, the event facilitated for an international, multigenerational discussion about systemic racism that was provoked by an engagement with early modern literature. That the attendees were free to participate from their homes while in lockdown provided further evidence, in my mind, for the remarkable pedagogical potential offered by the medium.

7 That a platform designed for video conferencing functioned so effectively this context is perhaps not entirely surprising. What remained unclear, however, was the utility of Zoom as a medium for artistic practice. Indeed, while the individual screens offered a window into the personal space of each reader, it was also unclear what connections might result from crafting a sense of collective or shared space between screens in a performance context. As a director who works frequently with site-specific performance, I was keen explore the opportunities and limitations of the Zoom space 
further. With this in mind, the company produced the first in its two-part "Isolation Across Borders" series ${ }^{4}$ with an online production of Macbeth on May 1.

8 Looking back on the Macbeth process, I am struck by just how steep the Zoom learning curve was during those first weeks and months. In addition to editing the play-text for a one-hour performance slot, the medium posed a number of logistical hurdles for the company to overcome. The first of these was creating a shared performance space. The company were broadcasting from a variety of locations which made creating a shared aesthetic difficult. ${ }^{5}$ We eventually worked out Zoom's virtual background settings and found a suitably foreboding backdrop that we felt brought the company of actors into the same narrative space. ${ }^{6}$

Figure 2

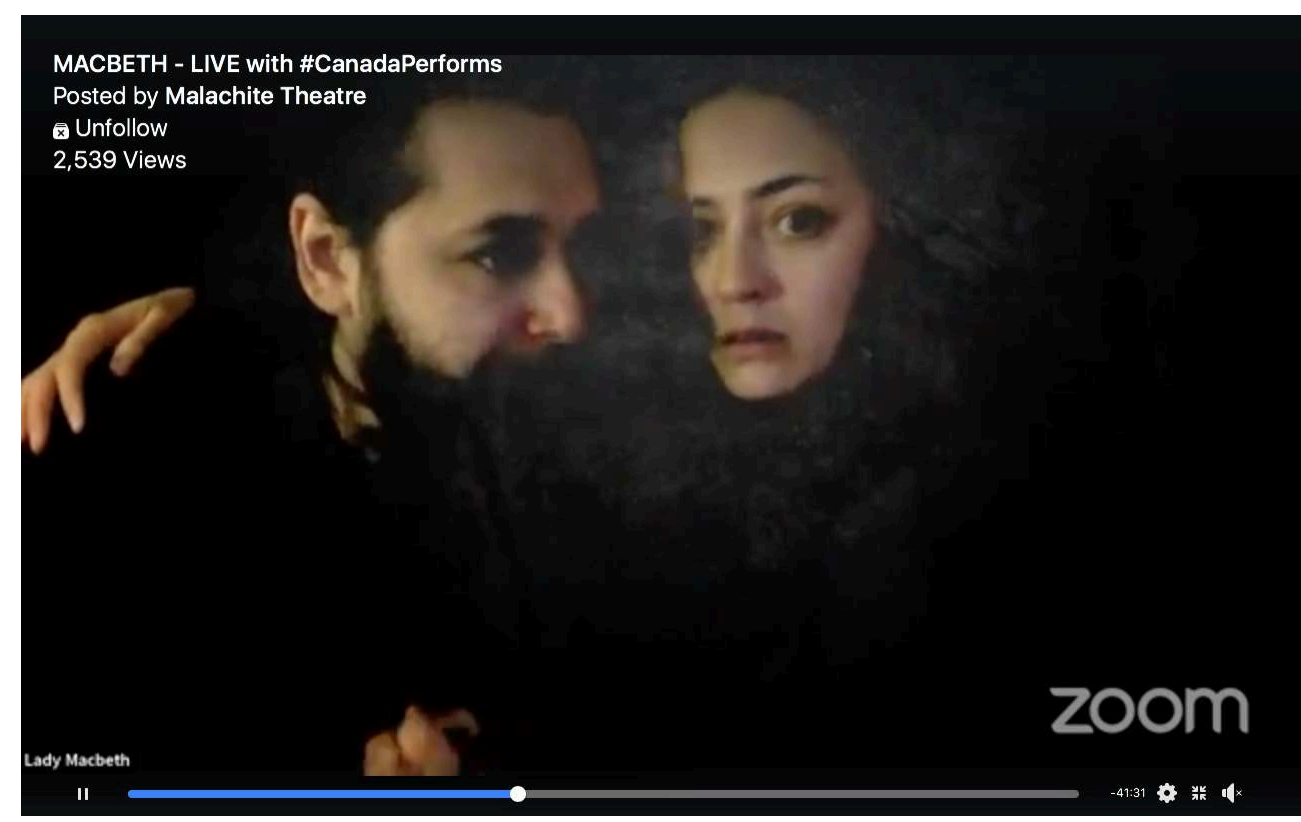

Malachite Theatre, "MACBETH- LIVE...", Facebook, May 1, 2020, www.facebook.com/ 466013643488097/videos/225869965371324

9 Again, this posed problems for accessibility and logistics. Many of the actors were able to source some form of green screen prior to performance, which helped unify delivery. Lady Macbeth (Danielle LaRose) was set apart by her performance space (a bedroom), which could not accommodate a green screen. Instead, we ran with this difference and explored ways to further set her performance space apart, such as the delivery of the "sleepwalking scene" (Macbeth 57:57-1:01:20) into a mirror. While we felt that the efforts taken by the company to bring the actors into a shared space were broadly successful, the intimate scenes were particularly effective in this context (25:10-31:06). This was certainly aided by the fact that Danielle and I live together and could share a single screen at narratively consequential moments. ${ }^{7}$

10 There are, of course, a number of complex staging requirements that were difficult to realize over the Zoom platform. The "banquet scene", the "apparitions' scene", any reference to Birnham Wood, and the climactic battle sequences, all had to be conveyed figuratively rather than naturalistically. This led to an additional emphasis on props, make up, gesture, and music. At the banquet for example, each actor drank from a similar style of glass (43:11-47:05). We experimented with camera angles and meta- 
theatricality more frequently in the series' second production (Hamlet- Live! 37:38-39:40), however the shoulder-up shots used in Macbeth lent themselves to accentuations of character through scarves, circlets, necklaces, and crowns. The production also used music to accent moments of particular drama or tension. As with a film or radio play, non-diegetic sound offered a heightened engagement with logistically complex scenes. Music and sound effects became increasingly central to the company's explorations in Hamlet as demonstrated by our work with the Ghost scenes (Hamlet Live! 15:55-23:26).

Figure 3

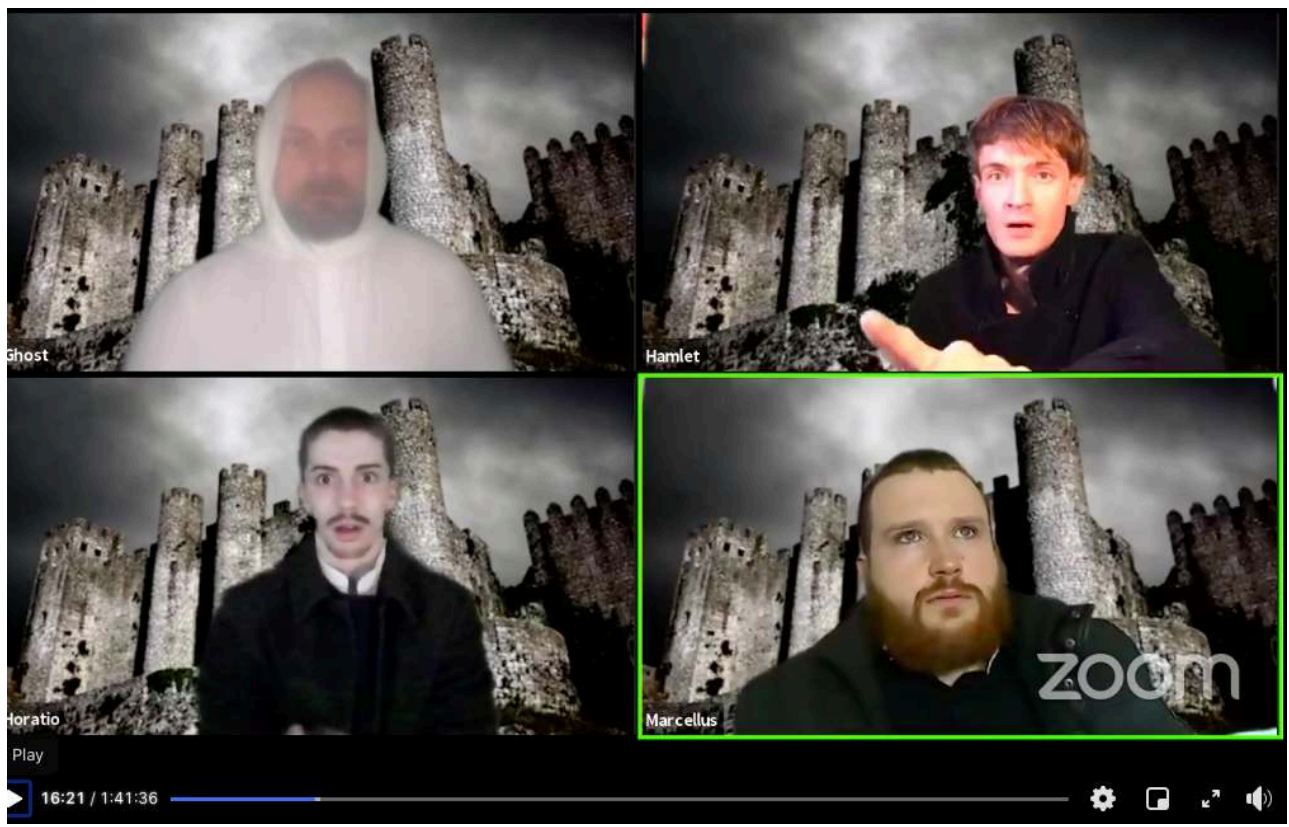

Malachite Theatre, "HAMLET- Live!" Facebook, May 30, 2020, www.facebook.com/466013643488097/ videos/720481605452690

11 Many of the technological and logistical issues that remained in Macbeth were worked out with practice. We decided to share the production in gallery view, which allowed the viewer to take in the entire scene in real time. Looking back, I regret not paying closer attention to these details, particular when handling asides (Macbeth 13:51-15:13). Furthermore, we had not yet resolved how to work with choric speech. The witches' scenes, for example, proved particularly difficult to adapt to Zoom's single microphone algorithm. Connection issues and lag also created problems early on, particularly with entrances and exits; but these were improved with rehearsal. Each actor was responsible for switching their camera and microphones on when entering a scene, and off when exiting. There were one or two moments where this proved problematic during the live production (10:10-10:45), however these were handled relatively well by the company. ${ }^{8}$ Finally, each actor changed their Zoom name to match the character in their scene, which helped the audience keep track of the story while accommodating for the doubling of roles.

12 The obvious limitations of the platform aside, the cumulative effect of the Macbeth performance on the company and its audience was remarkable. Indeed, aspects of performance practice developed in Macbeth started bleeding back into the subsequent 
weeks of Shakespeare Sunday. Participants began to switch their cameras on and off when entering and leaving a scene. Character names started to appear in place of the participants' usual Zoom username. Even singular costume items and props started appearing (notably at Shakespeare Sunday: Twelfth Night 1:34:56-1:38:06). ${ }^{9}$ The requirements and expectations of Shakespeare Sunday had not changed, but it became clear that the relationship between online practice and pedagogy was reciprocal.

Figure 4

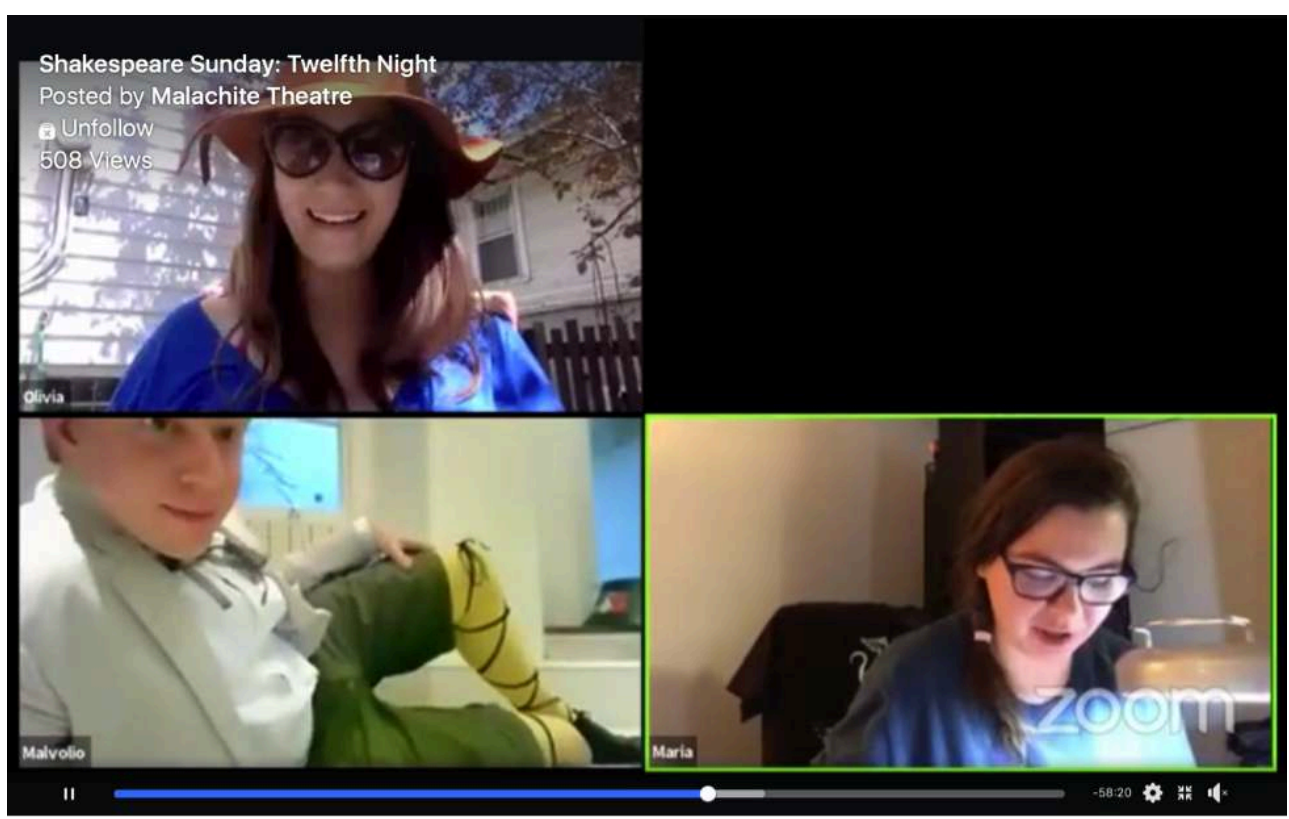

Malachite Theatre, "Shakespeare Sunday: Twelfth Night", Facebook, May 24, 2020 , www.facebook.com/466013643488097/videos/583413685617204

13 This was by no means a one-way process, however. A large proportion of the Macbeth actors were regular attendees at Shakespeare Sunday, and each remarked on how much sharper those events had made them at handling Shakespeare's dramatic text in an online context. Along with the ability to work on long-distance international collaborations, this is perhaps my most significant takeaway from a year of working with Shakespeare on Zoom. While the medium makes no pretence at replacing live theatre performance, it does provide an opportunity for actors to continue to hone their personal practice with early modern text in the interim.

Over the last year, then, the company has continued to encounter Shakespeare's plays at a distance. In some ways, working on Zoom reminds me of Bushy's remarks on perspective pictures in Richard II. Popular during the sixteenth-century, perspectives were unconventional paintings that appear distorted when viewed head-on but come clearly into focus when viewed from a specific angle. ${ }^{10}$ In Richard II, Bushy notes of perspectives: "when rightly gaz'd upon/ show nothing but confusion, eyed awry/ distinguish form" (RII, 2.2.18-20). So too, working on Zoom encourages us to eye our performance practices from new angles. By encountering, rehearsing, and playing with Shakespeare's texts in this new medium, I have discovered a renewed appreciation for the dramatic form of the language. While we cannot rightly gaze upon Shakespearean performance in the traditional sense, then, working on Zoom allows us the opportunity 
to return to basics, sharpen our skills with verse, and encourage international collaboration at a time of unprecedented isolation.

\section{BIBLIOGRAPHY}

“HAMLET- Live!” Facebook, uploaded by Malachite Theatre, May 30, 2020, https:// www.facebook.com/466013643488097/videos/720481605452690

“MACBETH- Live with \#CanadaPerforms." Facebook, uploaded by Malachite Theatre, May 1, 2020, https://www.facebook.com/466013643488097/videos/225869965371324

“Shakespeare Sunday: As You Like It!" Facebook, uploaded by Malachite Theatre, May 17, 2020, https://www.facebook.com/466013643488097/videos/708121076623389

"Shakespeare Sunday: The Merchant of Venice." Facebook, uploaded by Malachite Theatre, May 31, 2020, https://www.facebook.com/466013643488097/videos/246283713367008

"Shakespeare Sunday: Twelfth Night" Facebook, uploaded by Malachite Theatre, May 24, 2020, https://www.facebook.com/466013643488097/videos/583413685617204

“Shakespeare Sunday: Henry V." Facebook, uploaded by Malachite Theatre, 7 June, 2020, https:// www.facebook.com/466013643488097/videos/187621219229559

Shakespeare, William. King Richard II, edited by Peter Ure. Arden Shakespeare, Bloomsbury, 1988.

\section{NOTES}

1. Malachite Theatre is a site-conscious Shakespeare company founded in Shoreditch, London in 2013. More information can be found at www.facebook.com/malachitetheatre.

2. We began to share Shakespeare Sunday events on the company's Facebook Live page in May. Links to these later recordings are available below.

3. The majority of participants chose to work with the MIT online texts. Some readers preferred to read directly from a book, and there were no restrictions for any particular edition of that week's text. When leading the sessions, I would read out scene headings and major stage directions, so it was easy to intervene when minor irregularities occurred in that capacity.

4. The company's second production in the series, Hamlet - Live, was streamed on Facebook on May 31. Links to both performances are available in the bibliography.

5. Ben Waring (Ross) was broadcasting from a boat in Suffolk, for example.

6. Charles Cromwell (Duncan) conceived of this collective space through the somewhat tonguein-cheek term "theatre of the nth dimension", which proved so popular with the cast that it made it into the marketing copy for the performance.

7. Some may quite legitimately call this cheating. I prefer to think of it as dramaturgy.

8. This certainly added a layer of authenticity to the experience of live performance. With a view to preserving this quality for later study we have resisted the urge to edit out these sections in our archive footage. 
9. When not attending Shakespeare Sunday, Alex Peplow (Malvolio) moonlights as a corporate law barrister.

10. The National Portrait Gallery in London has a fantastic example of a perspective portrait of Edward VI, which can be viewed from a small spyhole in the glass at the side of the painting.

\section{ABSTRACTS}

Reflections on twelve months of early modern theatre practice and pedagogy during lockdown.

Retour sur les pratiques et méthodes de mises en scène d'œuvres de la première modernité durant le confinement.

\section{INDEX}

Keywords: Zoom, Shakespeare, Pandemic, Online, Digital, Theatre, Performance, Early Modern Drama, Pedagogy

Subjects: Theater

Mots-clés: Zoom, Shakespeare, pandémie, distanciel, digital, théâtre, performance, théâtre de la première modernité, pédagogie

\section{AUTHOR}

BENJAMIN BLYTH

University of Calgary

Doctoral student

Benjamin.blyth@ucalgary.ca 